\title{
Poder y escritura en la Edad Media
}

\author{
Blas Casado Quintanilla
}

La palabra se la lleva el viento, la escritura permanece y su significado puede ser entendido por todos aquellos que conocen el sistema de signos gráficos en que se ha escrito, no solo en vida del que lo escribió, sino también mucho tiempo después de la desaparición de su autor. La escritura puede ser estudiada, en primer lugar, como la representación gráfica de la palabra o como un conjunto de elementos gráficos aislados que conforman el alfabeto, es decir, las letras, con todas las variaciones de forma, ductus, módulo, ángulo y peso que éstos han sufrido a lo largo de los tiempos en la escritura manuscrita; en segundo lugar, como un sistema armónico capaz de expresar unas ideas que pueden ser captadas por el conocedor del sistema convencional de los signos utilizados. Estas ideas pueden estar contenidas en lo que denominamos documento diplomático, - conformar una obra literaria. Cada uno de estos grupos de producciones gráficas puede ser estudiado de forma independiente, aunque todas ellas estén vinculadas con la escritura, y en cada uno de estos casos pueden realizarse distintos enfoques, pero también pueden analizarse todos ellos desde una sola óptica: la de su relación con el poder.

Los paleógrafos estudian las formas antiguas de la representación gráfica de los fonemas, cuya unidad inferior es la letra en una escritura alfabética; dedican éstos su esfuerzo al análisis de la evolución de las formas que estos signos gráficos han experimentado a través de los tiempos; estudian también la manera de ligar las letras, las abreviaturas, el ductus, esto es, el orden y el sentido de los distintos trazos de una letra, el ángulo de la escritura y el ángulo de inclinación. Por esta vía distinguen varios tipos de escritura: visigótico-mozárabe, carolina, gótica, cortesana, procesal, humanística, etc. porque han existido otras tantas formas de signos gráficos; hablamos sólo del mundo occidental latino.

El concepto de escritura usado recientemente por los literatos es distinto al expuesto en el párrafo que precede. Para los literatos la palabra 
escritura es sinónimo de literatura. Esta es la obra literaria escrita con signos gráficos que representan el pensamiento, el raciocinio de la persona que observa, analiza, y estructura una forma de pensar que podría ser neutra, a favor o en contra del poder.

\section{ESCRITURA, PODER Y SOCIEDAD}

En las culturas antiguas, entiéndase las mesopotámicas y la egipcia, la «invención de la escritura aparece como obra de seres sobrenaturales» 1. Para los estudiosos sobre impacto de la escritura en las sociedades no caben dudas acerca de su importancia. Para Moorhousse «la escritura es preminentemente el arte de la civilización» ${ }^{2}$ tanto porque ha permitido la fijación de las creencias de un pueblo y la titerautra «como porque ha desempeñado una parte fundamental en la reorganización de los complejos estados de los tiempos antiguos y modernos", creando sociedades en las que la vida pública y privada han cambiado profundamente mediante la adquisición de la escritura. Sensu contrario, sin la escritura «no podríamos habernos apartado mucho de la situación de barbarie» ${ }^{3}$.

Por su parte Gelb, cree que «la invención de la escritura y de un sistema eficaz de indicaciones sobre papel, ha influido más en elevar la raza humana que ninguna otra proeza intelectual en el progreso del hombre... igual que el habla distingue al hombre del animal, la escritura distingue al hombre civilizado del bárbaro" ${ }^{4}$.

Su poder en las sociedades es tal que, «dondequiera que aparece la escritura va acompañada de un notable desarrollo del gobierno, las artes, el comercio, la industria, la metalurgia, variados medios de transporte, una agricultura desarrollada y la domesticación de los animales"... O dicho de otra manera la escritura existe solamente en una civilización y una civilización no puede existir sin la escritura» 5.

Durante mucho tiempo apenas si existía la cultura escrita y se confiaba todo a la memoria, aunque como sabemos era éste un recurso bastante precario. Este carácter de precariedad fue delatado ya por Esquilo, autor griego, que pone en boca de Prometeo los beneficios que la escritura ha

\footnotetext{
Moonhousse, A.C. Historia del alfabeto, Madrid Reimpr. Taurus, 1993, p. 245.

MoORHOUSSE, obr. cit., p. 245.

lbidem.

GELB, Y. Historia de la escritura, Madrid, Reimpr. Alianza Universidad,1987,p. 285.

ID p. 286.
} 
aportado a la humanidad, y lo hace con estas palabras: ..." y después descubri el número, el más excelente de los inventos, y la combinación de los signos, memoria de todas las cosas, madre laboriosa de las musas ${ }^{6}$, por tanto y en primer lugar, la función de las letras combinadas entre sí es la de registrar los acontecimientos; y en segundo lugar, la de inspirar a su vez ulteriores descubrimientos. Por su parte Eurípides señala también dos finalidades a las letras: uno es de orden utilitario, consignar por escrito precisas disposiciones testamentarias que evitan disputas familiares; y el segundo es de orden científico: "de tal manera que, sin haber atravesado la extensión del Océano, uno, quedándose en casa, puede llegar a conocer lo que sucede alli's por medio de las letras.

En la Alta Edad Media se conocen y recogen estas alabanzas del poder de la escritura y se rechaza el uso de la memoria, aunque se hiciera uso casi exclusivo de ella, de forma que, incluso en los propios documentos preparados y expedidos en aquel tiempo, y que por fortuna han llegado hasta nosotros, se recoge este pensamiento. En los preámbulos de estos documentos se subrayan dos aspectos: uno, la necesidad de poner por escrito los contratos de compraventa por seguridad de los contratantes, como en este caso: «Quamquam in omnibus difinitionibus fide sit maxime requirenda opportet tamen ut ea que inter emente et vendentem agantur scripture soliditate firmetur ut nec distraentium in postmodum aliqua sit repetitio nec comparatoris qualibet videatur esse formido" 7 ; y otro, por dejar constancia escrita de la necesidad de usar de la escritura y lo olvidadizo de la memoria, como ocurre en este otro documento: «Porque los reales fechos a los fieles sean perdurables, mester es que sean socorridos por ayuda de escriptura de la olbidança de malvestad" ${ }^{8}$.

Otro aspecto a estudiar respecto de la escritura y la sociedad, es conocer el grado de utilización de la escritura por parte de los miembros que compusieron la sociedad en la Edad Media. No es este un tema de interés menor, sino de preocupación constante en las investigaciones que sobre la escritura se están haciendo, no solo por parte de un importante grupo de Paleógrafos, sino también de Filólogos, en tanto que estudian la escritura desde una perspectiva del análisis social.

6 Esquilo, Prometeo, Versos 459-62.

Minguez Fernández, José María, Colección diplomática del monasterio de Sahagún. Siglos IX y X, Colección "Fuentes y estudios de historia leonesa" vol. 17, León 1976, p. 223. El documento es del 8 de octubre de 960 .

8 Julio GonzÁlez, Reinado y diplomas de Fernando III. Vol. II, Caja de Ahorros de Córdoba, Córdoba 1983, p. 204. El documento es de 22 de junio de 1222. 
Entre los varios aprendizajes que el hombre ha de realizar a lo largo de su vida, es el de la escritura el que está más rígidamente formalizado en una sociedad. Mientras que las demás cosas se van aprendiendo de forma gradual en la familia y en las escuelas, la enseñanza de la escritura ha de hacerse en la escuela. Para Cardona «el motivo más evidente de la rigidez formal que presenta la enseñanza de la escritura consiste en que ésta es un saber al que la sociedad atribuye un gran peso y que por lo tanto es un saber que debe enseñarse de manera conservadora para que nada cambie ${ }^{9}$ en el sistema gráfico de una comunidad, ni en la reproducción de las letras, ni en lo que hace a la ortografía.

La escritura es uno de los elementos del saber convertido en causa de prestigio social. El prestigio es una suma de connotaciones positivas. Así en la Edad Media gozaban de gran prestigio y eran mirados como superiores aquellos que tenían el dominio del arte de reproducir con soltura los signos gráficos. La escritura no es algo compartido igualitariamente, y en ciertas sociedades la escritura fue y es solo de un grupo, "de manera que la optimización no es ciertamente el primer objetivo que se fija quien la posee; por el contrario, la escritura debe ser compleja, difícil, exotérica, etc. Debe pues apartar al profano y de cualquier manera inspirarle veneración, respeto y hasta temor» ${ }^{10}$. En el buen entendimiento de que estas connotaciones no son consustanciales a la escritura sino un elemento sobrevenido a la escritura desde la sociedad que se sirve de ella; se convierte así el uso de la escritura en un instrumento de prestigio y de poder a favor de algunas personas y en detrimento de las otras.

En este mismo sentido, los indígenas del Continente Americano cuando llegaron los primeros misioneros españoles a aquellas tierras, los hombres con los que allí se encontraron entendieron la escritura como algo "mágico" y dotado de un poder extraordianrio a tenor de lo que se nos dice en éste y en otros pasages:

«Para suplir la memoria y falta de las letras (pues no las tienen) hacen que sus hijos aprendan y sepan muy de coro la manera de la muerte de sus hombres más destacados... diré de suso que no tenían letras antes que se me olvide de dezir lo que de ellas se espantan. Digo que quando algún christiano escrive con algún indio a alguna persona que esté en otra parte o lexos de donde se escribe la carta, ellos están admirados en mucha manera de ver que la carta dize acullá lo que el christiano que la

9 Giorgio R. Cardona, Antropología de la escritura, Gedisa, Barcelona, 1994, p. 108.

10 Ibid, p. 110. 
envía quiere; e llevanla con tanto respeto o guarda, que les parece que también sabrá dezir la carta lo que por el camino le acaesce al que la lleva" ${ }^{11 .}$

Tanto si es considerada como algo sobrenatural, como si es admirada por su poder mágico, la escritura, para aquellas personas que no la conocen, es portadora de un poder en si mismo y que va a beneficiar con idéntico poder a aquelia persona que es capaz de conocer y hacer uso de esos signos que llamamos escritura.

Hasta tal punto llega el poder de la escritura que cualquier conquistador se fija como uno de sus objetivos de conquista para destruir un pueblo el destruir sus tesoros escritos. "Así se entiende por qué Cortés, al conquistar Méjico en 1520, ordenó la quema de todos los libros aztecas que pudieran recordar a la población nativa su pasado glorioso; por qué la inquisición española, al enviar a los judios a la hoguera, quemaba con ellos sus libros talmúdicos; por qué los nazis deseosos de destruir las ideologías contrarias a las suyas, quemaron los libros de sus enemigos» ${ }^{12}$.

La Paleografía puede mirar hacia su propio objeto material, para realizar un estudio de la historia de la escritura, fijando el origen y la evolución por las que ha pasado a lo largo del tiempo. El paleógrafo mediante la observación atenta de las formas adoptadas por las letras en los distintos momentos de su utilización podrá llegar deductivamente a conclusiones válidas sobre su evolución. La práctica de la lectura comparativa entre manifestaciones escritas por diversas personas y en lugares próximos o separados entre sí facilitarán la visión de conjunto necesaria para poder determinar los cambios experimentados en una letra o letras a través de los tiempos. Le corresponde al paleógrafo explicar los fenómenos gráficos, señalar sus transformaciones y, también, buscar las causas que las produjeron, ordenándolo todo en un verdadero saber orgánico.

Por este camino algunos autores entre los que destacaremos a: Schiaparelli, Battelli, Cenceti, Casamassima ${ }^{13}$ han desarrollado una Paleografía como historia de la escritura. Estos autores y otros siguiendo

11 Gonzalo FERNANDEZ DE OVIEDo, Sumario de la natural y general historia do las Indias, Toledo 1526. Fácsimil, Madrid Espasa Calpe 1978, fol. 25 v.

12 GeLB, Y. Obr. cit., p. 301

13 G. Batello, Lezioni di Paleografía, Ciudad del Vaticano, 1949; G. CenCetTI, Vechi e nuovi orientamenti nello studio della Paleografia en La Bibliografía 50 (1950) 4-23; E. CASAMASSIMA y E. STARAZ, Varianti e cambio gráfico nella scrittura dei papir latini, en Scrittura e Civiltá 1 (1977) 9-15; A. PETRucci, Storia della scritura e storia della societá, en III Cursos de estudios universitario. Benassal, Castellón, 1985. 
el camino del análisis de la escritura han incorporando el concepto de que la escritura ha sido no solamente vehículo de cultura, sino que ha sido ella misma un espejo del nivel de cultura alcanzado por las sociedades que han creado los distintos tipos de escritura y que han ido fijando en el lenguaje escrito, lo que primero fue lenguaje hablado.

Desarrollando y ampliando la propuesta de Cenceti, y sin abandonar el objeto ya señalado de la Paleografía en su concepción actual, Petrucci ${ }^{14}$, Bartoli ${ }^{15}$, Cardona ${ }^{16}$ y otros autores, han incorporado a sus investigaciones paleográficas los aspectos de ciencia de la cultura y estructura social, a través del estudio de la historia de la escritura. Llaman la atención sobre el nexo existente entre el status social y el dominio del arte de la escritura ${ }^{17}$. Este planteamiento lleva a la Paleografía a elaborar una historia social de la escritura. La ausencia de la capacidad para realizar las letras por parte de algunos miembros de una sociedad, denota un nivel escaso de cultura; la balbuceante escritura que aparece en las suscripciones de los documentos de determinadas épocas, como ocurre en la Alta Edad Media, delatan otro nivel cultural; la escritura de documentos, la escritura de códices, el perfecto conocimiento de las fórmulas diplomáticas de aquellos y la belleza o pobreza, tosquedad y deficiencias de todo tipo en estos, hablan de distintos niveles de escritura y por lo mismo de distintos niveles culturales y sociales.

Así en la Alta Edad Media el instrumento de poder relacionado con el dominio del arte de escribir, era patrimonio de unos pocos entre los que cabe destacar, en primer lugar a los monjes y talleres monásticos, lugar en el que se refugió la cultura escrita. El desarrollo urbano y del comercio a lo largo del siglo XII y la aparición de las universidades a partir del siglo indicado y sobre todo durante el siglo XIII, produjo una cierta secularización de ese poder, aunque en ningún momento esta expansión signifique la alfabetización de un importante número de personas. Todo lo contrario, el número de individuos que poseían y conocían el arte de escribir era muy reducido.

Así podemos distinguir los siguientes estratos sociales: uno, el de aquellos que trazan una escritura de base o elemental; dos, la del grupo

14 A. PEtrucCl, La escritura tra ideologia e rappresentazione, en Storia dell'arte italiana II (1980) 17-23. ID, Alfabetismo ed educazione grafica degli scribi altomedievali (s. VII-X), en The role of the book in the medieval culture $V$ (1986) 109-132.

15 A. Bartolli Langel, Alfabetismo e cultura scritta nella storia della societá italiana. Perugia 1978.

16 G.R. Cardona, Per una teoria integratta della scritura, en Alfabetismo e cultura scritta II (1978) 51-74. ID, Sull etnografia della scrittura, en Scrittura e Civiltá I (1977) 211-218.

17 Petrucci, Lezioni di storia della escrittura latina, Roma, Reedición, 1985. 
humano que utiliza la escritura de manera usual; y tercero, la del grupo de los profesionales de la escritura. Así «la escritura es una de las formas de delatar las formas menos igualitarias en la distribución de los componentes de una sociedad, y su utilización es la que más evidentemente mostrará los condicionamientos y las presiones, las contradicciones y los desniveles del modelo social» ${ }^{13}$. Y esto porque el papel del escribiente se asocia con un estado elevado dentro de la sociedad, aunque ese status no esté concedido sólo por conocer y usar la escritura, «pero el oficio implica siempre una posición social elevada» ${ }^{19}$.

\section{LA FORMA DE LA ESCRITURA OBJETIVO DEL PODER}

En dos ocasiones históricas distintas y muy distantes en el tiempo, encontramos referencias a una intervención directa del poder político sobre la escritura: una a finales del siglo $X 1$ y otra a finales del siglo $X V$.

\subsection{Las crónicas latinas}

Las primeras crónicas de la Edad Media conservadas actualmente registran testimonios según los cuales la monarquía castellano leonesa participa directamente en la introducción del rito romano en aquel reino en sustitución del rito visigótico o toledano para la celebración de la misa cristiana. Vinculada a esta cuestión los cronistas relatan la presión ejercida por el poder político para la introducción en estos reinos de la escritura carolina o francesa en sustitución de la visigótico-mozárabe.

La Crónica del obispo don Pelayo de Oviedo dice que Alfonso VI "envió rápidamente embajadores a Roma a ver al papa Aldebrando que tenía por nombre Gregorio VII, porque quería introducir el rito romano en su reino. El nombrado papa mandó a España al cardenal marsellés Ricardo, el cual reunió en Burgos un concilio que confirmó el culto romano en todo el reino del rey Alfonso. Era MCXXIII (1085). Esto mismo se repite en la Crónica Najerense, mientras que en Chronicon mundi, de Lucas de Tuy se dice que se celebró un Sínodo en León (1090) en el cual: statuerunt etiam vt scriptores de caetero gallicam litteram scriberent

18 CARDONA, G.R., Antropología de la escritura, Barcelona, Gedisa, 1994, p. 87.

19 Ibidem, p. 89. 
et paetermiterent toletanam in officiis ecclesiasticis vt nulla esset diuisio inter ministros ecclesiae Dei. Texto en el que además de darnos la noticia de la determinación sinodal, se delata la ya existente división entre los escritores que seguían escribiendo un tipo u otro de letra, puesto que se pretende que no haya división y, a lo que parece, tensión. Esta misma noticia fue recogida por Rodrigo Jiménez de Rada, quien se extiende mucho en los pormenores y enfrentamientos habidos en Toledo durante el reinado de Alfonso VI a causa de la pretensión real de introducir el rito romano en sustitución del rito visigótico. Como es sabido de todos, la letra carolina, con independencia de que existiera o no la legislación sinodal citada, fue imponiéndose en lento proceso en todo el territorio castellano-leonés.

\subsection{Los Reyes Católicos}

A finales del siglo XV la Corona interviene de nuevo señalando la forma que habian de tener las letras usadas en la escrituración de los documentos. Esta noticia no la registran las crónicas sino diversos documentos como la tabla de derechos para los justicias y alcaldes de la Villa de Manzanares, de 1498; o los aranceles a los escribanos asturianos de 1494; a los de Badajoz de 1500, o la Pragmática real de 1503. Quieren los reyes que se escriba con letra cortesana, con un número determinado de líneas por página, y tratan de evitar el abuso de los escribanos en su utilización de la denominada escritura procesal que a todas luces les reportaba mayores ingresos porque cobraban a tanto el folio escrito.

\section{PODER Y DOCUMENTO DIPLOMÁTICO}

Dejando a un lado el campo de las letras y su reproducción, nos situamos ahora en uno de los ámbitos de elaboración y composición escrituraria de las que hemos hablado más arriba.

El documento diplomático más solemne fue el privilegio rodado, que es una creación pontificia, asimilada en el reino de León y de Castilla durante los reinados de Fernando II de León (1157-1188) y Sancho III de Castilla (1157-1158). Tomando este tipo documental como modelo, se estableció la sucesión de las distintas cláusulas diplomáticas. No hace ahora al caso recorrer éstas una a una; nuestra intención es fijar la atención en algunas de ellas. 
En cualquier documento diplomático, esto es, aquellos escritos que tienen naturaleza jurídica y que han sido redactados según unas normas, intervienen tres personas: el autor, el destinatario y el rogatario; aquellos ya los conocemos, éste es el que materialmente escribe el documento y que puede darle fuerza de prueba mediante la aposición de su suscripción o firma, porque así está autorizado para ello. A nosotros nos interesan las tres personas pero a distinto nivel.

El autor es el que hace o realiza la acción jurídica que después ha de consignarse en lo que nosotros conocemos por documento. Su presencia queda asegurada en la intitulación, en la disposición y en la validación documental. En cambio, el destinatario aparecerá en la dirección del documento y en la cláusula de la exposición.

Se dice que el documento es del autor y así es ciertamente; él es el reponsable de su contenido. Además de ver y estudiar el contenido de un documento, podemos observar en él otros aspectos que son aquellos que a nosotros nos importan ahora. No vamos a situarnos en el campo paleográfico o en el análisis de la tipología de la escritura con la que fue escrito, ni en la mayor o menor belleza en su presentación, ni en el soporte sobre el que se escribió, ni en su composición literaria. Solo atenderemos al estudio de la tensión de poder que se hace presente en cualquier documento diplomático. Seguimos en esta exposición el esquema propugnado hace ya diez años en el Congreso internacional de Ciencias Históricas celebrado en Munich, bajo el signo de la tensión existente entre los diversos colectivos que han conformado las sociedades históricas. A esta tensión se le ha dado el calificativo, que nosotros subscribimos, de "la alteridad en la historia». Esta alteridad se hace presente, como no podía ser de otra manera, en la propia estructuración interna de cualquier documento, ya que éste no es otra cosa que el vehículo de transmisión de las relaciones inter vivos de aquellos que hicieron la historia.

El autor del documento aparece en la intitulación con su nombre, su apellido o apellidos, y la enumeración de sus títulos o el cargo que ocupa dentro de la administración en la que ejerce su poder; si es el monarca con la expresión del origen divino de su poder: por la gracias de Dios, rey de, así indica el ámbito de la extensión hasta donde llega su influencia señalando el territorio o hasta dónde se extiende la fuerza del título que acredita su señorio; se presenta a sí mismo con todos los atributos con los que acredita su posición social y del poder que puede ejercer. Se dispone a dar a conocer a todos los que lo lean que el escrito, debidamente redactado, se convertirá en el brazo largo y en manifestación solemne de su 
poder. Observemos la diferencia existente entre estas intitulaciones, escritas en siglos distintos, y el reconocimiento escalonado del ámbito del poder del rey que en ellos va apareciendo:

Ego Adefonsus gratia rex una cum coniuge mea Xemena (Alfonso III, 904, noviembre, 30)

Ego Adefonsus, Dey gratia rex Legionis et Gallecie (Alfonso IX de León, 1211, marzo 3)

Yo don Alfonso, por la gracia de Dios rey de Castiella, de Toledo, de León, de Gallizia, de Sevilla, de Cordoua, de Murçia et de Jahen. (Alfonso $X, 1256$, octubre 30 )

La extensión de los dominios de la corona de Castilla y León irá aumentado a medida que avanza la reconquista y su desarrollo va a quedar de manifiesto en la enumeración de los reinos en los que ejercen su reinado; pero llegará un momento en que el poder real está bien asentado y ocurrirá, como en las cédulas reales, en la cuales la intitulación es tan sencilla como poderosa: El rey.

Cuando la escrituración de los documentos no está destinado al público, sino para que quede constancia de su existencia y para uso privado del personal de la cancillería, tal como ocurre con los libros de registro, entonces las intitulaciones pueden quedar reducidas a la mínima expresión del nombre acompañados del etc: Doña lsabel etc.; de donde podemos también concluir que, aparte de ahorrarse espacio y tiempo en la labor del registro de los documentos, al eliminar una parte integrante de la intitulación, su inclusión iba destinada precisamente a manifestar no solo la grandeza sino también el poder del rey; sensu contrario, podía haberse usado de la abreviatura en el documento destinado al público en general o a un destinatario particular.

El poder ha de ejercerse guiado por la razón y no de forma arbitraria, es la máxima antigua y el muro que mejor y más protege al titular del poder. Por ello es necesario exponer las razones que han movido al autor de la acción jurídica a realizar ésta y a ponerla por escrito para que su conocimiento se extienda a todos aquellos que han de sentirse afectados

Según Paoli la «parte espositiva e dispositiva» contienen el hecho documentado y es verdaderamente «el alma del documento» en cuanto que es un testimonio histórico. En el expositivo se contienen las motivaciones por las cuales el autor ha sido impelido a realizar y consignar el acto jurídico. $Y$ añade el citado autor que no mucho más puede decirse en cuanto a la sustancia intrínseca, porque el estudio y la valoración de esta parte del documento «appartiene piuttosto alla critica storica che non alla 
diplomatica» ${ }^{20}$. Floriano ${ }^{21}$ y Marin-Ruiz Asencio ${ }^{22}$ siguen en este punto al citado autor italiano.

Pratesi, rememorando a Paoli, dice que «la narratio o espositio» contiene el recuento de las circunstancias inmediatas que han inducido al autor a realizar la acción jurídica. Pero añade que por su naturaleza con frecuencia asume otros elementos y puede incluir en los documentos públicos el recuerdo de «la petitio» y de la «intercessio». Finaliza afirmando: «entonces constituye un válido elemento de crítica no tanto por su contenido histórico cuanto por su estructura diplomática» ${ }^{23}$. Ciertamente la «petitio» y la «intercesio», en sustancia, no son otra cosa sino una enumeración de motivos que han empujado al autor del documento a realizar el acto jurídico. Pero además de este valor, las cláusulas diplomáticas en cuestión, nos permiten conocer sendos pasos importantes en el proceso de elaboración del documento, y por tanto, son algo más que unas simples motivaciones que justifican el dispositivo al que han dado lugar.

El documento puede haber nacido de «motu proprio» del autor y entonces la cláusula de la exposición de motivos se convierte por este camino en el soporte racional de la acción del que ejerce el poder, cuando de su propia voluntad nace el documento. Suele ser frecuente, no obstante, que el documento nace a petición de parte, y es entonces cuando en esta cláusula pueden hacerse presentes las razones aludidas o esgrimidas por el destinatario en tanto que fue éste quien demandó y aportó las razones que podía presentar para pedir determinados beneficios al que ostenta la autoridad. Pero, ¿qué motivos aparecerán en la cláusula de la exposición del documento en cuentión? ¿Todas las que expuso el demandante o sólo aquellas que interesan dar a conocer y acepta el demandado? En la exposición de motivos presentada por el peticionario se haría una relación razonada de argumentación en la que se reflejaba los servicios prestados, sus aspiraciones, sus necesidades y sus esperanzas. En el documento de respuesta, el autor ha realizado una selección a través de la cual está ejerciendo su poder, al mismo tiempo que colocando los elementos necesarios para transmitir una imagen del demandante, la imagen

20 C. PaOli-G.C. Bascapa, Diplomatica, reimp. Florencia 1987, p. 108.

21 A. Floriano, Curso..., p. 271.

22 T. Marín, Ruiz Asencio y otros, Paleografía y Diplomática, T. II, reimp. 1990, p. 182.

23 A. Pratesi, Genesi e forma del documento medievale, 2a edición, Roma 1987, p. 82. Todavía nos importa volver sobre las palabras de este autor cuando afirma que el expositivo "puede incluir en los documentos públicos el reduerdo de la «petitio» y de la «intercessio». Palabras que nos llevarían a señalar, ¿sólo en los documentos públicos? A nuestro entender aparecen estos elementos clausulares en los documentos no catalogables como públicos. 
que al demandado le interesa que tenga el lector respecto del demandante. Esta imagen puede ser beneficiosa o muy buena para el destinatario, pero también puede ser neutra, mala o muy perjudicial para aquel a quien va dirigido. En cualquier supuesto ya se ha realizado la acción del poder que habíamos situado en manos del autor. Así Alfonso X, tras las peticiones formuladas por la caballeros de Avila, concede a éstos numerosas franquicias y exenciones por estas razones:

Porque fallamos que la villa de Avila non avie fuero complido por que se juzgasen ansi como devien tan buenos e tan onrrados como ellos son,... et demás por fazerles bien e merçet e por darles gualardón, por los muchos servicios que fizieron al muy noble e mucho alto e mucho onrrado rey don Ferrando, nuestro padre, e a nos antes que regnásemos e despues que regnamos,.. (Alfonso $X, 1256$, octubre, 30).

Con contenido bien distinto hemos recogido esta cláusula expositiva de un documento de los Reyes Católicos, que dice así: Sepades que Diego Martínez, el rico, vezino del Tiemblo, aldea de la çibdad de Avila, nos fizo relaçión por su petiçión que ante nos en el nuestro consejo presentó, dezyendo que él deve e es obligado a dar e pagar a Cristobal Beato e a Luys Ordoñez e a Fernando Ordonez, quinze mil e quinientos maravedis. E que por causa de algunas pérdidas que le han venido, está muy pobre y alcanzado (vemos que aquí se recoge la idea de pobreza porque le van mal los negocios pero no se nos dice qué tipo de negocios ni en favor de quién los hizo, aunque cabe colegir que, dada la buena imagen que de él están dando, el negocio fue favorable a los reyes) tanto e por tal manera que syn grande daño de su hazienda no podría pagar los dichos maravedis a los plazos a que está obligado, nin parte alguna dellos. E nos suplicó que por quanto los dichos acreedores diz que son personas ricas e cabdalosas que le pueden bien esperar por qualquier tiempo, syn gran daño de sus haziendas... por lo qual prorrogamos e alargamos los plazos e términos en que el dicho Diego Martínez es obligado de pagar los dichos maravedis... (1489, septiembre, 26) ${ }^{24}$.

Una cláusula expositiva bien distinta de la anterior la encontramos en un documento de la Caballería de Calatrava, del maestre Pedro Girón, en el que se nos pinta a uno que había sido de su confianza, con la peor de las imágenes y sin paliativo ni atenuante alguno:

24 Casado Quintanilla, B. Documentación medieval abulense en el Registro General del Sello, Vol V, Institución Gran Duque de Alba, Avila 1993, p. 164. 
Por quanto frey Alfonso, sacristán que solia ser del nuestro convento de Calatrava, cometió tan grandes e enormes delitos contra Dios e contra la dicha Madre de él e contra nos, non solo desobedeciéndonos, más aún dilapidando e destruyendo los bienes de nuestra orden e de la dicha sacristanía, auiendo ladrones e robadores en la casa de ella e de alli robando e reçebtando en ella los robos e quebrantando los juramentos de obediençia que a nos auía jurado e prometido, como a su maestre; e los ornamentos, cruçes e cáliçes del nuestro convento, sacándolos del dicho convento e robándolos, llevándolos a Villarreal por los convertir en sus usos propios, lo qual todo es notorio e como en fecho notorio... (Pedro Girón, maestre 1451, abril, 2).

En cuanto a la cláusula dispositiva tenemos que indicar que también sirve al diplomatista para clasificar los documentos en mandatos, en cartas misivas, en confirmaciones y otros, en tanto en cuanto las expresiones de la disposición adquieren una u otra formulación.

La cláusula dispositiva es aquella en la que el titular del documento expresa su voluntad, comunmente siguiendo una fórmula de mandato ejecutivo; aquella en la que aparece la razón de ser de la acción jurídica realizada y consignada por escrito. Aquí la tensión ha dado a su fin y se manifiesta el poder en toda su amplitud. Para nuestro objetivo actual es esta la cláusula en la que el autor nos dará la imagen que el quiera darnos de sí mismo, la que más le guste o la que necesite dar en las circunstancias del momento. Vinculado al dispositivo o mandato aparece las cláusulas penales a las que se someterán aquellos que contravinieren los anteriormente ordenado, punto en el que, a veces, se trasluce una situación personal del autor del documento.

El estudio conjunto de la parte expositiva y dispositiva del documento diplomático nos ha brindado la ocasión de presentar una reflexión más sobre la estrecha vinculación existente entre las distintas cláusulas diplomáticas. Ya en el año 1985, tomó carta de naturaleza entre los historiadores, el concepto de «el otro» y el de la «imagen» en la historia ${ }^{25}$. Estas dos cuentiones aparentemente no tienen nada que ver con la actividad investigadora a realizar por el diplomatista. Pero, ya se ha dicho, «las apariencias engañan».

Si la presencia del "uno» se constata en la intitulación y en la disposición; la del "otro» queda reflejada en la dirección y en la exposición. A esta relación entre el «uno» y el «otro» se le ha llamado «la

25 Congreso Internacional de Ciencias Históricas, Sttutgart, 1985. 
alteridad» ${ }^{26}$. Mientras que la cláusula expositiva contiene la «petitio» y la «intercessio» o las razones alegadas por «el otro», el dispositivo contiene la voluntad del «uno", del titular del documento. La propia nomenclatura de las cláusulas antes aludidas denota la existencia de la relación entre dos personas de distinto nivel de poder; en la «petitio» hay una persona que pide y otra que recibe la petición; en la «intercessio» se muestra igualmente la existencia de una necesidad de apoyo en una tercera persona para que la demanda llegue con fuerza ante el que ostenta el poder.

De ordinario conocemos el contenido de la demanda de «otro» sólo a tenor de lo que el «uno» recoge en la exposición; por este camino, el lector del documento, nosotros, sólo conoceremos aquellas razones y motivos que, expuestos por el "otro", quiere o interesan destacar al "uno» y a su juicio deben pasar a formar parte del expositivo. Así el «uno» estará creando en nosotros, los lectores, una « imagen» del otro, la que a él le interese o le convenga, aunque sea de forma involuntaria. Si desde esta perspectiva, releemos los expositivos de los documentos ya leidos en otra ocasión, nos daremos cuenta de que se nos ha quedado una imagen concreta, con independencia de una valoración histórica, de «el otro» que aparece en cada uno de ellos. Al igual que a través de la lectura del dispositivo, se nos ha creado una imagen del «uno», pero en este caso, la que él ha querido trasmitirnos

De esta manera considerado, el documento aparece como un organismo vivo y dinámico; mientras que visto desde la óptica de un formulario, al que por otra parte siguen fielmente, queda reducido a algo mecánico y artificioso. Estamos convencidos de que el formulario no se construyó de forma casual, sino que su elaboración obedece a este esquema más profundo. A nuestro entender un formulario es el resultado de la estructuración en un conjunto de cláusulas de todo un complejo mundo de las relaciones entre "el uno" y «el otro", no importa que sean personas individuales o grupos; aquellos formularios son consecuencia de un reconocimiento de la estratificación social en cuyo entramado existe un «uno» y un «otro», esto es, un poder y un destinatario de la acción de la persona que ostenta el poder.

\section{LA CANCILLERIA REAL, UN CENTRO DE PODER DISPUTADO}

Alejandro Dumas en sus estudios de diplomática ${ }^{27}$ expone su pensamiento de que para conocer mejor y más profundamente los documentos

26 E. Benito Ruano, De la alteridad en la historia, Madrid 1988. Discurso de ingreso en la Real Academia de la Historia.

27 DumAS, A. La Dimplomatique et la forme des actes en Le Moyen Áge, 3a serie, XLIII (1932) 5-31. 
es necesario penetrar en el interior de las propias cancillerías, ver sus interioridades, las personas que preparan y expiden los documentos y el orden entre ellos, así como las tensiones que en este organismo se producen, si es que llega el caso.

Sabemos nosotros que en este organismo real existían: uno o varios cancilleres, varios notarios, muchos escribanos y otros muchos oficiales. Así lo delatan los propios documentos y lo afirman los relatos cronísticos de la época. Estas crónicas nos hablan de lo que en relación con el poder, tanto en el uso como en el abuso, sucedía en el en torno cancilleresco. Presentan a la cancillería como un instrumento de poder, vinculado a la preparación y expedición de los documentos, y como un lugar que concitaba las aspiraciones de control por parte de muchas personas de entre los grandes de la corte real. No es de extrañar. Los documentos son el brazo largo del poder real. Mediante ellos el rey daba órdenes, premios y castigos; favorecía y elevaba a los unos y hundía a los otros.

Recogeremos en este apartado una serie de párrafos cronísticos en los que aparece esta disputa de los grandes del reino por controlar la preparación y expedición de los documentos reales. Suelen los cronistas poner el énfasis en todo lo que hace relación a la validación de los documentos y en especial en la importancia del sello apuesto a los documentos, pero también se detienen en otros aspectos documentales. Con sus descripciones y observaciones, tanto en uno como en otro sentido, lo que indican es que los documentos de los que hablan son un instrumento de poder y que su existencia crea tensiones de poder entre aquellas personas que están en su entorno.

El infante don Felipe, hermano del rey Alfonso X, se había reunido con algunos grandes del reyno de Castilla y se habían ido para el reino de Granada. Para esta ida al citado reino «fueron fechas carta entrellos una en arábigo y otra en ladino» ${ }^{28}$, cartas en las que "porque sea firme e non venga en dubda, escrevimos en esta carta letra de nuestras manos. E yo el infante don Felipe e los ricos omes sobredichos, posimos en ella nuestros sellos colgados" ${ }^{29}$. Estos grandes de Castilla asi desnaturados del reino, una vez avenidos de nuevo con su rey castellano "pidieron al rey de Granada que, porque era postura entre el rey don Alfonso de Castilla e él que non acogiesen a ningunos ricos omes nin caballeros que fuesen desavenidos de su rey, pidieron al rey de Granada que les diese a romper

28 Crónicas de los Reyes de Castilla, BAE, T. LXVI, p. 32.

29 Ibid, p. 33. 
las cartas de postura que avian con él, porque le guardasen esta postura al rey e los ricos omes fuesen sin verguenza" " ${ }^{30}$. Una vez que todas las gestiones de concordia fueron arregladas «dió a romper la carta que le fue entregada de las posturas que eran entre el rey de Granada e don Felipe e don Nuño e los otros que fueron a Granada" ${ }^{31}$, manifestando por esta vía el poder que el propio documento suscrito tenía para la conservación de su buen nombre.

En otro relato se nos dice que Alfonso $X$ hizo todos los preparativos necesarios para ir a ser coronado emperador; entre otras determinaciones dejó a su hijo Don Fernando fijo primero heredero, por señor e por natural de todos, en su lugar de rey, e que bien sabien commo le avían recibido por rey e por señor después de sus días... "e para que él pudiese poner oficiales, dejole la una tabla de los sellos, e mandole que con ella pusiese los oficiales diciendo en las cartas que eran del rey; e que las mandara dar el infante don Fernando, primero heredero; e las otras cartas que oviere menester de enviar por los reinos sobre las querellas que antél viniesen e sobre las otras cosas que oviere a mandar facer en los reinos, mandó que don Fernando las enviase selladas con su sello" ${ }^{32}$.

En otra ocasión el rey Alfonso X, se acercó a Bayona para entrevistarse con el rey de Francia y dejó en Valladolid «un sello de los suyos con sus oficiales, e libraron cartas para todo el reino en gran poridad, en que envió mandar que todas las aljamas de los judios fuesen presos en un día de sábado" ${ }^{33}$. ( Esta orden de prisión la había dado porque los judios habían entregado a su hijo el infante Sancho, después rey Sancho IV, Ios dineros de la recaudación).

Entrando ya en la crónica de Sancho IV, el bravo, el cronista destaca en primer lugar que este rey convocó cortes nada más acceder a la corona, y con motivo de este acontecimiento "mostró el rey don Sancho en cortes muchas cartas e muchos previllejos que él mismo dió por premia que le ficieron, también Hermandades como concejos e otros muchos omes, e consejáronle que los revocase, e él revocolos todos, e mandó que gelos trojiesen, e rompiolos todos" ${ }^{34}$.

Sancho IV se fiaba mucho, dice el cronista, de don Lope, señor de Vizcaya, y éste pidió al rey que le hiciese conde y le diese algunos

\footnotetext{
Ibid, p. 36

Ibid, p. 47

Ibid, p. 48.

Ibid, p. 58

Ibid, p. 70 .
} 
puestos en la corte como el mayordomazgo y la alferecía para ordenar toda su caballería y el rey «dióle demás una llave de la chancillería de los sus sellos» ${ }^{35}$.

En un momento de discordia con los grandes del reino que se prolongó por algún tiempo, el rey Sancho IV y aquellos grandes se avinieron, y el rey se fue para Galicia y "dejó al Conde don Lope en Castilla, e dejó con él al obispo de Astorga e al deán de Sevilla, que era su notario mayor en Castilla, con la chancillería, porque librasen todos los pleitos en la tierra" ${ }^{36}$. Unas páginas más adelante vuelve a aparecer un elemento más "e el deán de Sevilla, que era notario mayor del rey en Castilla e tenie sus sellos» ${ }^{37}$. Ya en el mes de abril del quinto año de reinado de Sancho IV, aparecieron las diferencias entre el conde don Lope y el rey; bajo simulación el rey quiso atraer al conide a su fidelidad, aunque por exigencias del Conde, a las que el rey simuladamente se avino, aquel pidió al rey "que mandase traer una tienda alli a Loberuela, e sus sellos e los libros, e que alli gelo librase, e el rey tóvolo por bien" ${ }^{38}$. A los cuatro días el rey dió muerte al Conde Don Lope.

En abril de 1289 el rey tenía una entrevista en Bayona con el rey de Francia y con ocasión de ella "mandó que la su chancillería e todos los sus oficiales que se fuesen para Burgos, porque librasen ý todos los pleitos que en la tierra acaesciesen" ${ }^{39}$. En todos estos relatos cronísticos se pone de manifiesto que los documentos y la cancillería, como origen de los mismos, eran considerados como un instrumento de poder real; por ello el cronista deja constancia de lo que ocurría en el ámbito de la documentación de origen real.

Los documentos falsos también podían ostentar el poder de un documento auténtico. Según los cronistas eran muy frecuentes las desavenencias de algunos grandes con su rey. Durante el reinado de Sancho IV, también encontramos relatos de situaciones similares a las referidas a otros reinados, aunque en esta ocasión con algunos elementos nuevos y de interés para poder situar el poder concedido a los documentos y el principal soporte de la autenticación documental, radicado en los propios sellos que aquellos portaran. Así en abril de 1291 un hombre de Ubeda llamado Ferrand Pérez, dijo al rey "que sabía cúales e cuántos eran los

\footnotetext{
Ibid, p. 74.

lbid, $p .76$.

Ibid, p. 79 .

Ibid, p. 78

Ibid, p. 80 .
} 
ricos omes e caballeros e otros omes de cibdades e villas que enviaban cartas a dan Alfonso, su sobrino, que querian tener su carrera e voz, mostrole algunas cartas de algunos de ellos en quienes el rey mucho fiaba... e cuando el rey las vió, fue muy maravillado, e ovo dello muy gran saña... e el rey fízole a este Ferrand Pérez mucho bien". Pero la alarma causada por estos documentos se desvaneció pronto porque un hombre que venía con este Ferrand Pérez «habló con el rey en poridad, e díole la enemiga e falsedad en que este Ferrand Pérez andava, e dijole que le non creyese ninguna carta de aquellas que él le mostraba; que supiese por cierto que ninguno de aquellos omes buenos que él decía, que nunca le erraron, mas que éste con sabiduría falsa, por gelos perder todos, que ficiera sellos falsos de cada uno dellos, e que él se facía las cartas cuales él quería, nombrando que las enviavan ellos a don Alfonso, e que los sellos que él ficiera que los traía consigo. E el rey cuando esta razón oyó a aquel ome, plúgole dello, mandó prender luego a aquel Ferrand Pérez, e falláronle los sellos fechos de los ricos omes e de los más señalados de su reino; e cuando lo mandó comezar a atormentar, confesolo todo, e confesó más, que él ficiera otro sello falso de Enrique Enriquez en que ficiera sus cartas, e que las echara en el camino por do el rey avía a pasar... e que estas cartas que las cobrara el rey; por lo cual prendió a Enrique Enriquez, e oviéralo de matar, si non porque falló que el su sello era desvariado un poco de aquel de que estaban selladas las cartas; a acordándose el rey de esto que pasara así, e veyendo la falsedad con que este Ferrand Pérez andava, mandólo matar» ${ }^{40}$.

Durante el reinado de Juan II de Castilla encontramos otro caso de falsificación de documentos. A lo largo del año 1422, cuando el infante don Enrique se dio cuenta de que nada podía hacer sino volver al lado del rey Juan II, le pidió una carta de seguro a éste y se fue para la corte. El rey, reunido el Consejo, comenzó a decir algunas razones: a mi ha llegado noticias de algunas cosas «e algunos de los caballeros que han estado con vos, tratavan en gran deservicio mío e daño de mis reynos, las quales en ninguna manera cumplía que yo pasase so disimulación... antes es necesario que yo sepa la verdad... E para esto es mi merced que vos sean leidas unas cartas que me fueron dadas. Las quales tenia Sancho Romero, secretario del rey, el qual dixo que gelas había dado don Diego de Fuensalida, obispo de Zamora, las quales eran quatorce, e algunas dellas eran mensageras del Condestable don Ruy López Dávalos para el rey de Granada e para caballeros moros, e otras eran para algunos caballeros de

40 Ibid, p. 85. 
Castilla, las quales todas parescian firmadas del nombre del Condestable e selladas con su sello; el efecto de las quales era haciendo mención cómo el Condestable habia escrito al rey de Granada por sus mensageros,... e parescía por ellas que en diversos tiempos embiara hacer relación al rey de Granada quel infante don Enrique e los que con él eran rescibian grandes agravios del rey; que gelo hacian saber a fin de haver de él algún remedio e ayuda, el qual era quel rey de Granada entrase poderosamente en la. tierras del rey (de Castilla) e que para ello había favor del Condestable e de sus amigos,...” El resultado fue la prisión del infante. Pero todavía en este pasage se asegura más la importancia y el poder del documento en tanto en cuanto el rey se ocupa de mandar que se requisen todas las escrituras que pudieran tener consigo los implicados, tal como se nos dice a continuación: y el "rey mandó embargar todo lo de su cámara, e mandó tomar todas las escrituras, pensando hallar alguna cosa que tocase en las cosas dichas; e asi mismo mandó embargar todo lo de Garcifernández Manrique e tomar todas sus escrituras,..." y escribió cartas dando orden de prender al Condestable don Ruy Lopez Dávalos. Unos días después se prendió a "Juan García de Guadalaxara, que habia seydo secretario del condestable, el qual habia hecho todas estas cartas e falseado el nombre y sello del condestable como aquel que bien lo conocía; e fue traído preso a la villa de Valladolid, donde fue metido a tormento, e confesó él haber hecho todas aquellas cartas, e por cúyo mandado, e lo que se le había dado por ello; la qual confesión fue guardada en gran secreto, de manera que lo cierto dello no lo pudo saber el que esta crónica escribió”.

Durante el reinado de Fernando IV encontramos también algunas cuestiones relativas a lo que hemos dado en titular el poder de la escritura documental frente a la palabra dada por personas, incluso destacadas del reino, de la cual se hacen eco los cronistas de la época. A comienzo del reinado el infante don Juan pretendía el reino y de hecho se proclamó rey de León. Hubo acuerdo y el infante don Juan renunció a sus pretensiones reales «e de ésto fizo pleito omenaje ante toda la corte... e demás fizo jura sobre los santos Evangelios e sobre la cruz... e de ésto fizieron cartas muy firmes por ante cinco notarios que estavan presentes» ${ }^{41}$.

En este mismo sentido y con posterioridad fue el infante don Enrique quien para alcanzar algunos beneficios que pretendía había levantado ciertos movimientos entre el rey y la reina María, madre y tutora del rey, lo

$41 \quad$ Ibid, p. 117. 
que acabó en acuerdo con el rey Fernando, "e la carta fecha ficieron omenaje, e selléronla todos con sus sellos, e la reina tomó la carta porque no la oviesen don Enrique ni ninguno de los otros nin porque pudiesen obrar por ella de allí adelante» ${ }^{42}$. Ya habíamos observado que a las cartas-documentos se les concede un gran poder, bien porque se les colocan varios sellos, bien porque son suficientes para matar a algunos en caso de falsedad de las mismas, bien por otras razones que hemos visto; ahora se nos dice expresamente que los documentos tienen un gran poder, o dicho de otra manera, aquellos que los poseen pueden ostentar el poder al que se hace referencia en los documentos. La reina-tutora consciente de este poder guarda la carta para que nadie pueda usar de este documento.

La enfermad que acarrearía la muerte al infante don Enrique, seguimos en el reinado de Fernando IV, dio ocasión a que el cronista recogiera otro pasaje de gran interés para el tema que ahora nos ocupa, por estar implicado Don Juan Manuel, hombre de letras y gran conocedor de la importancia de los documentos y la escritura en general. La reina madre quería que el infante don Enrique, a su muerte, diera todos los castillos y villas al rey Fernando IV. El infante, por su parte, quería dárselos a su sobrino don Juan Manuel. La reina madre envió a unos caballeros de su confianza para que convencieran al moribundo infante que procediera de la manera por ella deseada y estos enviados de la reina "cuando llegaron a Roa, fallaron a dor Enrique con su dolencia muy grande, e empeoraba de cada día, e fablaron con aquel frayle que era su confesor, e respondioles que lo faría asi como la reina gelo enviaba mandar. E a todos cuantos eran con don Enrique metieron estos caballeros a que gelo aconsejasen, salvo a un caballero de Toledo que decian Alfonso Díaz, que era muy su privado, porquél consejaba todos los pleitos que él quería facer contra el rey, e tenía los sus sellos"; este caballero era a favor de que el infante don Enrique le diera sus catillos y villas a don Juan Manuel, al que avisó de todo. Cuando don Juan Manuel llegó a Roa «e vio a don Enrique, fallolo sin fabla e que non conosçía ya a ninguno, e cuidando que era muerto, tomole cuanto le falló en la casa, plata e bestias, e cartas que tenía blancas del sello del rey, e salió fuera de la villa e levó consigo cuanto y falló de don Enrique, e fuese para Peñafiel" ${ }^{43}$. Era don Juan Manuel hombre entendido en el quehacer documental y conocía su importancia, razón por la que el cronista no deja escapar la ocasión para hacer un relato minucioso acerca de las cosas que concitaron el interés del posible beneficiario de los bienes del difunto. 
Alfonso XI comenzó a reinar cuando tenía un año largo y durante su minoría ocurrieron muchas cosas; entre las que a nosotros atañen ahora, recogemos algunas. Quedaron por tutores del rey-niño: la reina doña María, su abuela, y sus tíos los infantes don Pedro y don Juan, con las siguientes condiciones: "Acordaron que el rey que lo cobrasen (estava en poder del obispo de Avila y en esta ciudad), et la crianza dél que la oviese la reina doña María, su agüela, e non otro ninguno; et que la chancilleria del rey que estoviese con el rey, et que non usasen de aquellos sellos que traian, et que los quebrasen; et que tomasen cada uno cartas blancas para los pleytos que librasen en las villas onde cada uno dellos fuese tutor, et que cada uno dellos usasen en las villas a do lo tomaron por tutor. Et ésto fue propuesto et firmado por todos los concejos de la una parte e de la otra, ... » ${ }^{44}$.

Todavía en el mismo año de 1311, en Burgos se pasó esta cuestión por Cortes y allí "quebraron los sellos que cada uno de ellos traía, et ordenaron que non oviese y otro sello ninguno sino aquel, et que siempre estoviese la chancillería con el rey et con la reyna; et que las alzadas veniesen todas ante el rey, et que tomasen el infante don Juan et el infante don Pedro cartas blancas cada uno de ellos en sendos lugares... et que por aquellas cartas non podiesen dar tierras nin dineros, nin facer rentas de gracia ninguna; et que las gracias et tierras et dineros se ficiesen por el sello del rey con acuerdo de todos tres los tutores... et desto ficieron pleyto et omenaje et juro todos los personeros de los concejos que y fueron, et levaron ende cuadernos sellados del sello del rey, et de todos tres tutores, porque fuesen ciertos todos los de la tierra en cómo avian de facer..." ${ }^{45}$.

Una vez que el rey llegó a la mayoría de edad, se reunieron los grandes del reino y los tutores y "dieron al rey las cartas blancas que tenían selladas con el sello del rey et con que ellos usaban de las tutorias" ${ }^{46}$.

El año 1407, durante el reinado y minoría de edad de Juan II de Castilla y de León, eran tutores la Reina madre doña Catalina y su tío, el infante don Fernando (después rey de Aragón). Conforme a lo determinado en el testamento de Enrique III de Castilla "hicieron del reyno dos partes e cupo a la Reyna de los Puertos contra Castilla e al infante contra el Andalucía... la reyna decía que la chancillería debia quedar en Segovia como el rey lo dexó mandado; y el Infante decia, que pues él iba a la guerra e havia de regir tan gran provincia, que era razón que todos los oficiales fuesen con él,

44 lbid, p. 178.

45 lbid, p. 179.

$46 \quad$ lbid, p. 198. 
asi la chancillería, como contadores mayores e contadores de cuentas, y sello y registro. E acordáronse que con el infante fuese un contador mayor,... e fueron con de los oidores de la chancilleria... y el sello mayor de la chancillerfa fue dado a Juan González de Acevedo para que lo llevase. E ordenaron que quedase toda la otra chancillería en Segovia y el sello de las tablas de plomo. E porque el infante iba a la guerra, e tales cosas podían hacer algunos de los ricos-hombre e caballeros en servicio del rey porque les debiese hacer merced por ello, e les hubiese a dar sus cartas e previllejos sellados con sellos de plomo, porque fuese exemplo e cada uno curase de bien facer, por ende ordenaron que fuesen dadas al infante cincuenta cartas de pergamino blanco,selladas con las tablas de plomo para 10 que dicho es, las cuales él rescibió e dió conoscimiento dellas a la reyna y las mandó entregar al doctor Juan González Acevedo, el qual dio conoscimiento dellas al infante porque diese cuenta dellas» ${ }^{47}$. Con esto el Infante Don Fernando tenía en sus manos el instrumento de poder, pero también se acordó hasta dónde alcanzaba realmente el poder de las parte de la cancillería que con él iba: "E otrosí, que todas las cartas que el dicho infante diere en los hechos que tocan a la dicha guerra, asi de llamamiento de gente e caballeros y escuderos, hijosdalgo e vallesteros, e de lievas de pan e otros pechos, $y$ en todo lo otro que fuese necesario espediente para la dicha guerra, que sean guardadas e cumplidas en las provincias e obispados e cibdades e villas e lugares que sean e caben en la administración de la Provincia de la dicha reyna-madre" ${ }^{48}$. Por esta vía quedaba fijado la importancia de los poderes concedidos a los documentos que pudiera preparar y expedir el infante, a pesar de llevar una pequeña parte de la canciIlería del rey. Cuando el infante don Fernando fue declarado rey de Aragón y se incorporó a este reino "él como tutor del rey don Juan de Castilla con la reyna su madre, determinó de dexar por sí en la corte del rey don Juan personas para que por él regiesen... y dejó el sello mayor de la puridad y escribanos de cámara a Fiui López e Alvaro García de Vadillo; e a Alvaro de Santa María dexó el registro, en tal manera que todos los oficiales quedaban asi enteros, como si por su persona alli estuvieran, e la reyna madre del rey teniendo la chancillería, que había siempre de estar donde el rey estuviese, según la ordenanza que el rey don Enrique habia dexado" ${ }^{49}$.

Durante el reinado de Pedro I de Castilla, unos cuantos grandes del reino se aliaron con Doña María, madre del rey, y Doña Blanca, primera

\footnotetext{
Crónica de los reyes de Castilla, BAE, T. LXVIII, p. 284.

Ibid, p. 285.

lbid, pp. 345-346.
} 
mujer del rey, y con Doña Leonor, reina de Aragón y tía del rey Pedro Y, y se situaron en Toro lugar al que pidieron al rey que se fuera para tratar algunas cosas tocantes al reino. El rey tras algunas dudas se presentó en Toro. El rey fue directamente al palacio donde moraba su Madre, la reina María, y alli mismo los que le esperaban trataron del asunto que más les interesaba para cambiar el rumbo en la gobernación del reino, Así lo dice el cronista: «e ordenaron estos señores los oficios de la casa del rey en esta guisa alli luego antes que el rey partiese del palacio de la reyna su madre: que el maestre de Santiago don Fadrique fuese camarero mayor del rey; e que el infante don Ferrando fuese chanciller mayor, e mandaron prender a don Ferrand Sánchez de Valladolid fasta que le diese los sellos; e que el infante don Juan de Aragón fuese alférez mayor del rey, e entregáronle los pendones,... E el rey estaba muy apretado ca non le dejaban fablar con muchos de los que venían a él, e el rey teníase por preso, porque veía que un tan gran señor como el maestre su hermano quería ser su camarero; ca tales oflcios siempre los ovieron caballeros llanos, e nunca tan gran señor como el maestre de Santiago fuera camarero mayor del rey, fasta que el maestre su hermano lo quería ser... el rey cabalgó un día de gran mañana para ir a caza; e facía ese día gran niebla; e desque se vió alongado de la villa acució el andar quanto pudo e fue camino de Segovia..." ${ }^{50}$. Todavía el cronista insiste en la importancia de la cancillería señalando que cuando el rey se fue para Segovia dejo la cancillería en Toro, pero que el rey « desque llegó a Segovia envió sus cartas a la reyna doña María, su madre, e a los otros que y eran, que le enviasen su chancillería e sus sellos, e si non, que sopiesen que él podría bien aver plata e fierro para facer otros sellos. E los que estaban en Toro enviáronle sus sellos, e mandaron a los chancilleres e notarios que se fuesen para él; e así lo ficieron» ${ }^{51}$.

Este acto de reclamar su cancillería y el detalle con que el propio cronista narra el acontecimiento muestra la verdadera importancia de la cancillería, al tiempo que destaca quiénes eran los que realmente ejercía el oficio de cancilleres; observemos como los de Toro, según se dice, «mandaron a los cancilleres e notarios que se fuesen", mientras que el infante don Fernando de Aragón, canciller mayor al efecto, no se fue para el rey en este momento, por tanto eran otras las personas que ejercian de cancilleres, tanto del sello mayor del rey como del sello de la poridad. El rey reclamaba la cancillería y los sellos porque ahí residía su poder como rey

5o Pero López de Ayala, Crónicas, Madrid, Planeta, 1991, pp. 135-138.

51 Ibid, p. 138. 
en tanto en cuanto cualquier carta que llevara el sello del rey, como hemos visto más arriba, tenía fuerza de orden real, hubiera sido dado con su consentimiento o sin su autorización.

Algunos documentos tienen el poder de vida o muerte para aquellos a quienes van dirigidos. Así Pedro I de Castilla cercó la villa de Toro donde estaba, la reyna su madre y algunos otros caballeros entre los cuales se encontraba «Rui Gónzález de Castañeda que estaba con la reyna, e avía traido su pleytesía secretamente antes de esto con el rey, e tenía un alvalá suyo de perdón, e esforzábase en aquel perdón, e dixo a la reyna: Señora id al rey ca no lo tenemos en al. E la reyna salió del alcázar e venía con ella e los otros que venían cerca della; e Rui González traía el alvalá del rey de perdón que le avía enviado antes de ésto en la mano alta, diciendo que el rey ge lo enviara, e le perdonara por aquella alvalá; pero decía el rey que el tiempo que él pusiera a Rui González de Castañeda para se venir a la su merced que era pasado e que ya non valía el alvalá,..., e un escudero que decian Alfonso Fernández del Castillo, llegó a Rui González de Castañeda e dióle con un cuchillo por la garganta, e derribole e matole» 52.

\section{PODER Y LITERATURA}

Bajo el título «poder y escritura» se han celebrado varios congresos o reuniones científicas. Entienden los autores que en ellos han participado que la escritura ha estado al servicio o en la oposición al poder. Así en un coloquio internacional celebrado hace algunos años en Aix-en-Provence ${ }^{53}$ bajo el rótulo arriba expresado se continúa en la línea de investigación ya iniciado en 1981, año en el que la Universidad de Provenza había reunido a un grupo de especialistas de la historia de la literatura al amparo del epígrafe «El poder y la pluma». Abundando en esta misma idea se celebró otro congreso en el año de 1986, pero ahora desde la óptica de «el escritor y su público". Leidos los tres títulos congresuales juntos nos damos perfecta cuenta de que estas "asambleas" científicas han reunido en tres ocasiones a varios historiadores de la literatura, palabra esta última que ha sido voluntariamente transliterada por la de escritura.

Por esta vía las obras que a lo largo de los tiempos han recibido el nombre de literarias se las denomina ahora con la palabra escritura y los

52 Ibid, pp. 165-166.

53 Ecrire a la fin du Moyen-Age. Le pouvoir et l'ecriture en Espagne et en Italie (1450-1530). Aix-en-Provence, 20-22 de octubre de 1988. Publicado en Universidad de Provenza 1990. 
congresos aludidos han dado ocasión a presentar las obras literarias o a los autores de las mismas, bajo los auspicios de sus vinculaciones, de adulación o de rechazo, con el poder; dicho de otra manera, en estos coloquios se ha abordado el estudio de las circunstancias que han permitido a los autores escribir, al mismo tiempo que se analiza la naturaleza del discurso, favorable o no favorable, en relación con el poder, en toda su complejidad; se incluye el estudio de las obras poéticas de carácter cortesano en las que se presenta unas reivindicaciones, incluso de estimulación de unas revueltas, en abierta oposición al poder del momento, al mismo tiempo que otras composiciones poéticas hacen de sus mecenas figuras idealizadas adornadas con un sin número de virtudes.

Otro de los participantes en este congreso ${ }^{54}$ marca la diferencia entre los escritores de la segunda mitad del XV y los de finales del XV y principios del XVI. Entre los primeros situa a los escritores políticos, esto es, intelectuales y militares políticamente comprometidos como es el caso de Alonso de Cartagena, Rodrigo Sánchez de Arévalo o Alonso de Palencia; entre los segundos sitúa a los escritores protegidos, de origen generalmente más modesto como Juan del Encina y Gil Vicente, sujetos al poderoso que les protege y al que dedican sus loas.

En los artículos a los que nos estamos refiriendo se expone la idea de la existencia de "un vínculo entre poder y escritura, lo que constituye una parcela de la sociología literaria, por cuanto puede contribuir a esclarecer, en alguna medida, la conexión entre literatura y sociedad» ${ }^{55}$. Se trata de estudiar el enlace social entre la literatura y la sociedad del tiempo en que aquellas obras fueron elaboradas; dicho de otra forma es un análisis sociológico del hecho literario.

La justificación del estudio de lo social en la escritura, léase literatura, no necesita ser acreditado porque el escritor «vive y escribe en un medio social concreto y, por otra parte, la literatura, al ser historia viva, se produce en un contexto preciso y en una sociedad con unos problemas singulares de orden social, político, económico y religioso" ${ }^{56}$. Desde esta óptica se puede plantear el estudio de ¿quién escribe?, ¿qué escribe?, ¿para quién se escribe?.

\footnotetext{
54 Pierre Heugas, Le passage $d^{\prime}$ un siècle à l'autre: des écrivains politiques aux écrivains protégés en lbid, pp. 123-134.

55 Nicasio Salvador Miguel, Poder y escritura en España a mediados del siglo XV. El caso del Cancionario de Estúniga, en Ibid, p. 31.

so Ibid, p. 32.
} 
La justificación no invalida la enumeración de «los peligros que acechan a la sociología de la literatura, desde transformarse en sociología aplicada ejercida por aficionados hasta convertir el estudio sociológico en un fin en sí mismo; desde tomar como causas hechos que no pasan de ser simples condicionantes hasta manipular el texto al servicio de una determinada ideología, y, sobre todo, olvidar que al historiador de la literatura le incumbe, antes que nada, indagar la especificidad del individuo creador, de la obra literaria y de sus modalidades expresivas» 57 .

57 Ibid, p. 33. 